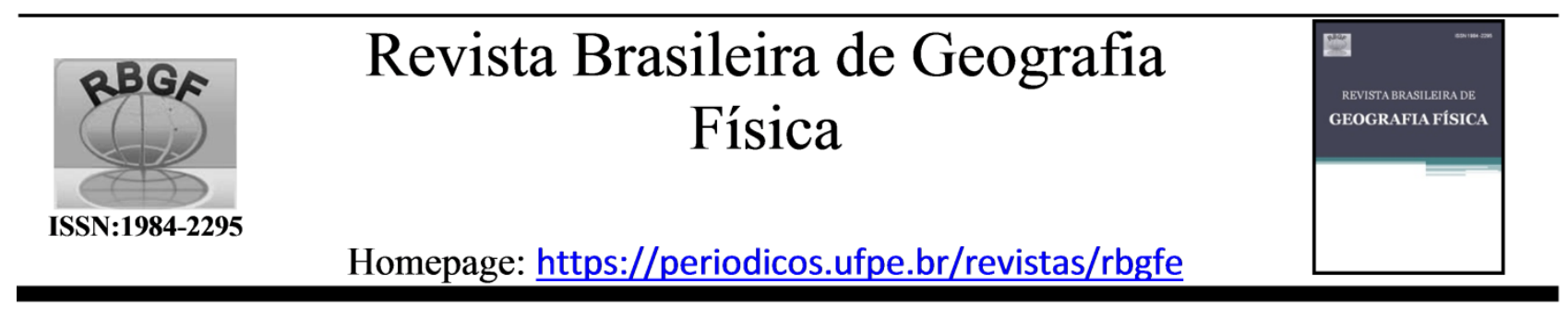

\title{
Classificação de estilos fluviais na bacia do rio Bananeiras (alto vale do Rio São João, Silva Jardim - RJ): base para análise da condição geomorfológica
}

\author{
Carolina Ramos Menezes-Universidade Federal Fluminens. Autor correspondente: e-mail: \\ crmenezes@id.uff.br, Carla Maciel Salgado-Universidade Federal Fluminens
}

Artigo recebido em 20/09/2018 e aceito em 22/05/2019

\begin{abstract}
Resumo
O presente estudo tem como objetivo aplicar a metodologia de classificação de estilos fluviais para subsidiar a análise da condição geomorfológica na bacia hidrográfica do rio Bananeiras. Este rio é um dos afluentes do alto vale do rio São João, no município de Silva Jardim (Estado do Rio de Janeiro). A metodologia dos estilos fluviais empregada compreende uma análise multiescalar, envolvendo a caracterização das condições de contorno relacionadas ao contexto da bacia e do ambiente de vale. Após as análises, no rio Bananeiras foram identificados 5 estilos fluviais com características distintas de caráter e comportamento: (1) confinado com cabeceiras íngremes, (2) confinado com planícies de inundação ocasionais, (3) não confinado com baixa sinuosidade, (4) não confinado com meandros arenosos, (5) não confinado retificado. Os estilos fluviais confinados apresentam uma condição de estabilidade geomorfológica relacionada ao confinamento do vale, ao leito rochoso e à cobertura florestal. Os canais não confinados com baixa sinuosidade e com meandros arenosos são mais sensíveis, ocorrendo ajuste lateral por processos erosivos e deposicionais. O estilo não confinado retificado é pouco sensível, pois apesar da sinuosidade do talvegue do rio, não há ajuste à baixa declividade e ao não confinamento do canal. Os resultados apontam que a diversidade de estilos fluviais identificados está relacionada aos controles regionais, como condições de geologia, relevo e precipitação. Tais resultados permitem uma melhor compreensão da dinâmica fluvial do rio Bananeiras, o que pode favorecer a implantação de estratégias adequadas de planejamento e gestão do sistema fluvial.
\end{abstract}

Palavras-chave: Vale fluvial. Ajuste fluvial. Sensibilidade. Comportamento do rio.

\section{River styles classification in Bananeiras river basin (upper São João river valley, Silva Jardim - RJ): basis for geomorphic condition analysis}

\begin{abstract}
The present study aims to apply the river style classification methodology to support the geomorphic condition analysis in Bananeiras river basin. This river is one of the tributaries of the upper São João river valley, in Silva Jardim municipality (Rio de Janeiro State). The employed river styles methodology includes a multiscale analysis, involving the characterization of the boundary conditions related to the context of the basin and the valley environment. After the analyzes, 5 river styles were identified with distinct characteristics of character and behavior: (1) confined with steep headwaters, (2) confined with occasional flood plains pockets, (3) laterally unconfined with low sinuosity, (4) laterally unconfined meandering, (5) laterally unconfined channelized. The confined river styles present a geomorphic condition steady related to the confinement of the valley, the rock bed and the forest cover. Unconfined channels with low sinuosity and meandering are more sensitive, with lateral adjustment by erosive and depositional processes. The laterally unconfined channelized style is not very sensitive because, despite the thalweg sinuosity, there is no adjustment to the low slope and to unconfinement of the channel. The results indicate that the diversity of river styles identified is related to regional controls, such as geology, relief and precipitation conditions. These results allow a better understanding of the fluvial dynamics of the Bananeiras river, which may favor the implementation of adequate river system planning and management strategies.
\end{abstract}

Keywords: River valley. River adjustments. Sensitivity. River behavior. 


\section{Introdução}

Os estudos de geomorfologia fluvial têm sido levados a um nível alto de complexidade devido à combinação de tipos de clima, relevo e geologia, que geram uma gama de processos e formas específicas dos ambientes fluviais. Nesse contexto, classificações mostram-se importantes no sentido de organizar e diferenciar os ambientes em grupos que podem ser comparados e interpretados para fins de melhor compreensão da dinâmica fluvial e planejamento satisfatório. Para lidar com essas questões, as pesquisas em geomorfologia fluvial vêm adotando a dinâmica hierárquica dos trechos para análise da organização dos sistemas fluviais (Frissel et al., 1986; Marçal e Lima, 2016). Essa perspectiva consiste na ideia de que os sistemas são apreendidos como elementos dispostos em diferentes níveis de organização. Ao longo da década de 1990 emergiram novos modelos de classificação e análise de rios visando identificar as relações entre processos e formas. Rosgen (1994) e Brierley e Fryirs (2000) apontaram para a perspectiva de que os rios ocupam um importante lugar e função dentro do contexto da paisagem e da bacia hidrográfica.

Nesse sentido, um dos principais objetivos do sistema de classificação proposto por Rosgen (1994) seria fornecer o mecanismo para avaliar o comportamento de um rio através de sua aparência. Assim, a classificação já pretendia prever adequadamente as respostas geomorfológicas às perturbações do sistema, o que foi considerado pioneiro na década de 1990. No entanto, a abordagem de Rosgen (1994) não explica o comportamento do rio inserido num contexto espacial ou evolutivo, enfatizando apenas a aparência do canal e desconsiderando a conjuntura regional associada.

Posteriormente, Brierley e Fryirs (2000) apresentaram uma versão modificada da abordagem de Rosgen (1994) para a classificação de segmentos fluviais, avançando na investigação acerca da história evolutiva do sistema, bem como as perturbações a que foi submetido ao longo desta.

\section{Material e métodos}

\section{Área de estudo}

$\mathrm{O}$ estudo foi realizado na bacia do rio Bananeiras, inserida no alto vale do rio São João, à montante da represa de Juturnaíba (Figura 1). A bacia do rio Bananeiras, que é uma das principais
Nesta abordagem ocorre o esforço metodológico de integração de escalas, refletindo o reconhecimento de que um rio faz parte de um sistema físico com uma história evolutiva (Brierley et al., 2008). A metodologia de classificação de rios, denominada "estilos de rio" (river styles), vem se destacando, pois fornece um modelo geomorfológico no qual as relações espaciais e temporais dos processos biofísicos são avaliadas dentro de um contexto de captação, destacando as trajetórias evolutivas do sistema fluvial (Brierley e Fryirs, 2000; Brierley et al., 2008). De forma geral, o método propõe a classificação de segmentos do rio visando à interpretação da forma, comportamento, condição e potencial de recuperação de um rio.

Durante sua trajetória evolutiva, os sistemas fluviais brasileiros, na maioria das vezes, passaram por alterações na sua condição geomorfológica "natural" devido à crescente demanda para o desenvolvimento socioeconômico. No estado do Rio de Janeiro, especialmente ao longo do século $\mathrm{XX}$, as bacias hidrográficas tiveram seus rios profundamente alterados pela intensificação de programas de canalização e retificação, além de outros impactos negativos causados por diferentes formas de uso e ocupação do solo. Nesse contexto, uma crescente demanda por estratégias de gestão de bacias hidrográficas e a utilização da metodologia para classificação de tipologias fluviais vem ganhando destaque. Tal metodologia permite compreender as interdependências que ocorrem entre os diferentes trechos do rio desde a nascente até a foz, considerando as especificidades de cada trecho, o que favorece ao melhor planejamento e gestão ambiental nas bacias hidrográficas.

Considerando o exposto, o presente estudo tem como objetivo aplicar a metodologia de classificação de estilos fluviais (river styles) para subsidiar a análise da condição geomorfológica na bacia do rio Bananeiras (município de Silva Jardim, RJ).

da margem esquerda do rio São João, ocupa área aproximada de $80 \mathrm{~km}^{2}$ e é classificada como $4^{\mathrm{a}}$ ordem (segundo metodologia de Strahler, 1952, apud Stevaux e Latrubesse, 2017). 


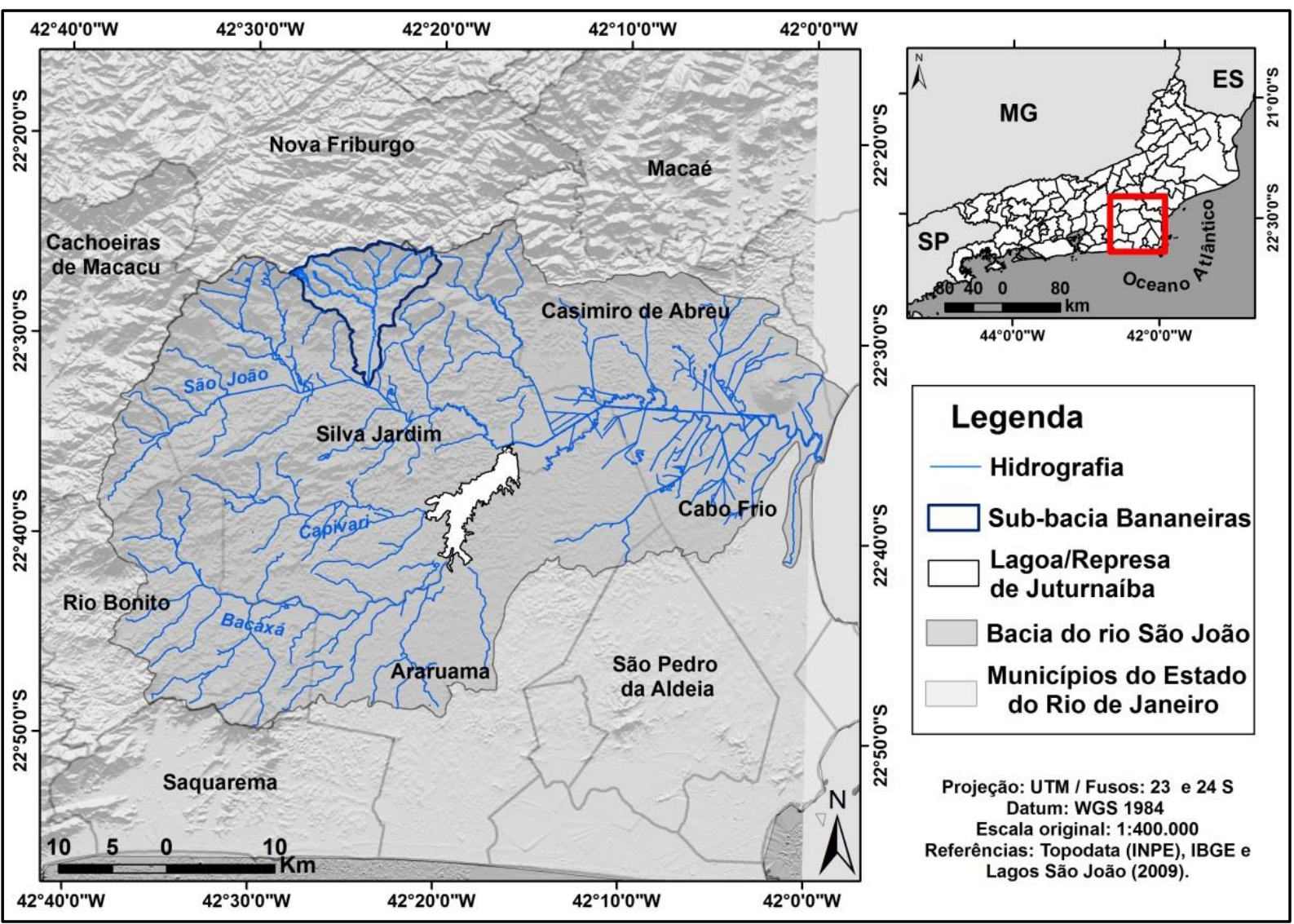

Figura 1 - Localização da bacia do rio Bananeiras inserida no alto vale do rio São João.

\section{Classificação fluvial}

$\mathrm{Na}$ abordagem da classificação do rio adotada, o caráter e o comportamento do rio são analisados a partir da identificação, interpretação e mapeamento das tipologias fluviais em toda a bacia hidrográfica, seguida da avaliação da condição geomorfológica de cada estilo na bacia hidrográfica (Brierley e Fryirs, 2000). Esta metodologia de classificação de estilos fluviais (river styles) vem sendo utilizada em algumas pesquisas (Brierley e Fryirs, 2000; Brierley et al., 2002; Lima e Marçal, 2013; Kleina et al., 2014; Marçal et al., 2017) no intuito de avaliar a condição geomorfológica de sistemas fluviais, bem como criar cenários futuros analisando as variáveis neles inseridas. Para a interpretação de sistemas fluviais, destacam-se dois níveis escalares hierárquicos (Figura 2): $i$ ) a escala regional (bacia do rio São João) tem como principal objetivo organizar informações sobre caracterização ambiental, considerando aspectos de geologia, geomorfologia, clima, bem como uso e ocupação da terra; ii) a escala local (rio Bananeiras) permite levantar informações sobre a característica do vale, feições morfológicas no canal, forma em planta e material do leito. 


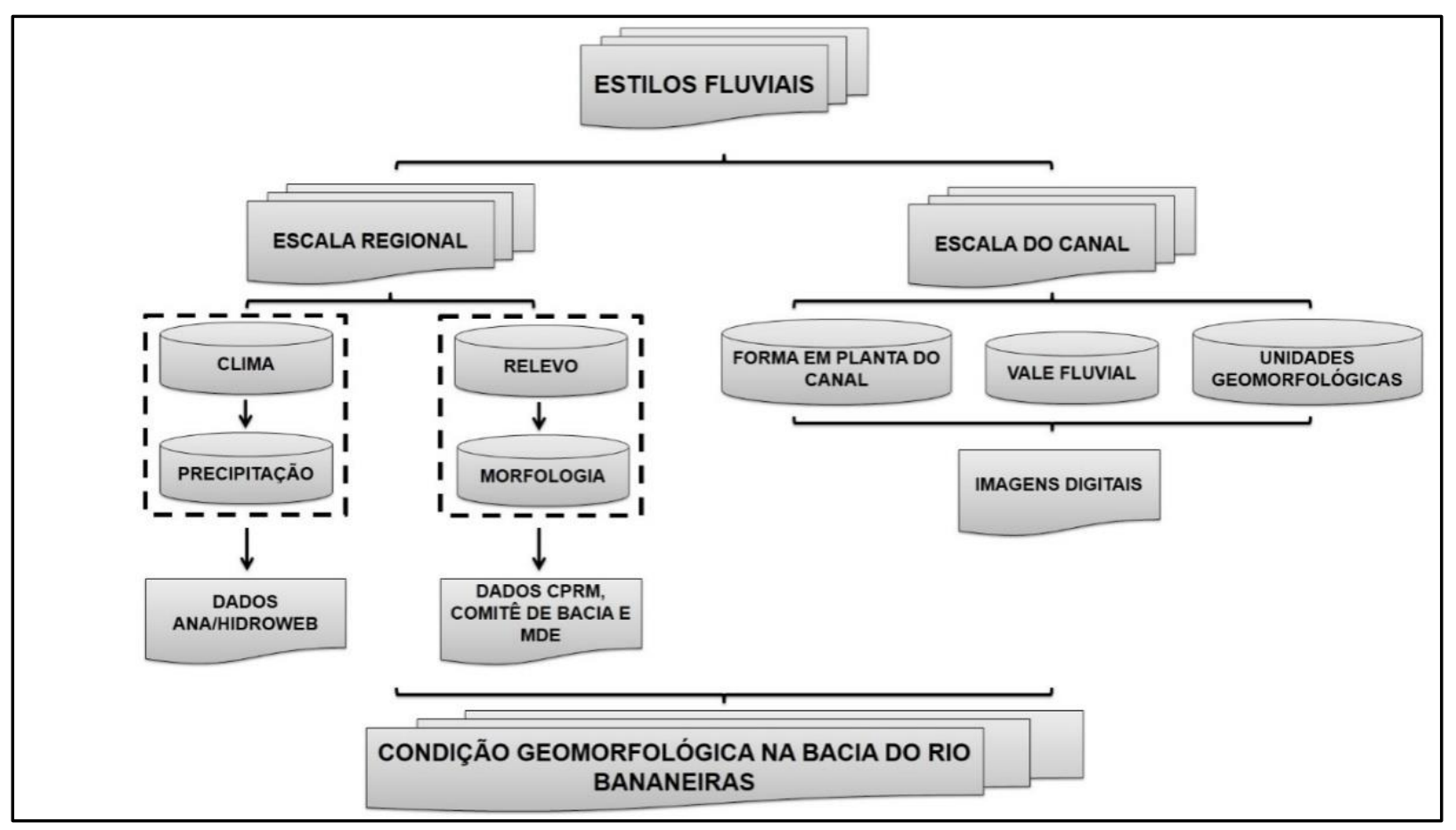

Figura 2 - Fluxograma metodológico aplicado no presente estudo.

Para fins de caracterização regional da área de estudo foram considerados aspectos geológicos, geomorfológicos, climáticos, de uso e ocupação da terra da bacia do rio São João. Neste caso, foram utilizadas bases cartográficas de geologia e geomorfologia disponibilizadas em portais eletrônicos da CPRM, escala 1:100.000.

No sentido de caracterizar o comportamento da precipitação na região, realizouse um levantamento da série histórica de precipitação no portal eletrônico da Agência Nacional de Águas (ANA). O período temporal da série histórica compreende 1968 a 2015, somandose mais de 30 anos de dados mensais e diários. Através dos dados de chuva de três postos pluviométricos (Gaviões, Piller e Quartéis) da ANA/CPRM instalados em regiões adjacentes à bacia do rio Bananeiras, foram calculadas as médias anuais e mensais da série histórica. Os dados obtidos foram trabalhados no software Microsoft Excel, através do qual foram realizados todos os cálculos e gráficos.

A caracterização geomorfológica do ambiente fluvial (escala local) foi realizada por meio de imagens de alta resolução disponíveis no Google Earth Pro. Foram identificadas diferentes configurações de vale, forma em planta e a presença de unidades geomorfológicas no canal. A vetorização dos canais inseridos em cada estilo foi realizada no próprio Google Earth Pro por meio da ferramenta 'adicionar caminho'. Os arquivos foram gerados no formato *.kml e convertidos através da ferramenta 'kml to layer' no software ArcGis 10.1 para o formato shapefile. Essas etapas foram realizadas visando à elaboração de um mapa final de estilos fluviais, relacionado a uma tabela onde são detalhadas algumas características existentes em cada um deles.

Uma campanha de campo foi realizada no mês de janeiro de 2017 com o intuito de adquirir perfis topográficos no ambiente fluvial do rio Bananeiras, considerando o trecho mais acessível ao canal. Para o levantamento topográfico foi utilizada uma estação total, dispositivo caracterizado pela combinação de um teodolito e um MED (Medidor Eletrônico de Distância). No estado do Rio de Janeiro, o levantamento das seções transversais foi utilizado por Oliveira (2005) e Marçal (2013) com o objetivo de analisar mudanças na área e forma do canal, nos rios São João e Macaé respectivamente. No caso do presente estudo, os perfis auxiliaram na caracterização das feições no ambiente fluvial.

Com base na diversidade de informações analisadas, foi realizada a avaliação da condição geomorfológica relacionada, no presente trabalho, à capacidade de ajuste do canal fluvial aos aspectos regionais e locais.

\section{Resultados e discussão}




\section{Geologia, relevo e clima}

De acordo com caracterização elaborada por Silva e Cunha (2001) para todo o estado, a bacia do rio São João ocupa predominantemente região cujos domínios geológicos são Serra do Mar e Região do Lagos (Figura 3). O domínio Serra do Mar é composto por granitóides pós-tectônicos, circunscritos na bacia, de idade cambriana. As rochas integrantes do Domínio da Região dos
Lagos são constituídas predominantemente por gnaisses mesoproterozóicos. Os depósitos quaternários recobrem os fundos de vales, e são compostos por sedimentos arenosos e lamosos, eventualmente com cascalheiras, localizados em regiões de baixa declividade e ao longo das drenagens.

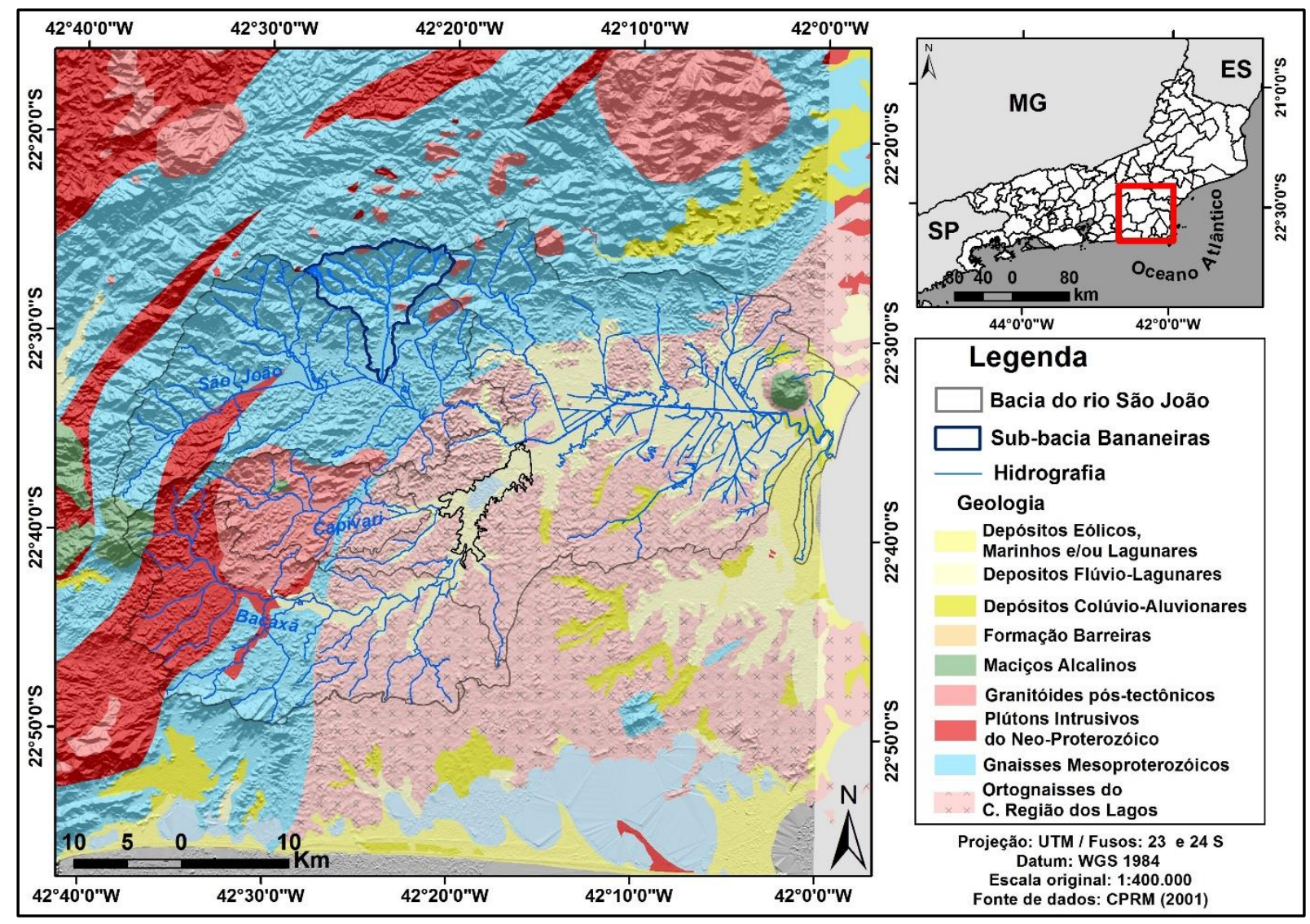

Figura 3 - Geologia na bacia do rio São João, onde está inserida a bacia do rio Bananeiras.

Em relação à geomorfologia, ficam evidentes quatro domínios geomorfológicos (Figura 4). O domínio montanhoso predomina ao norte, onde se formam as principais nascentes da bacia. O relevo montanhoso é sustentado por rochas alcalinas, englobando as escarpas do reverso da Serra do Mar, onde os terrenos são extremamente acidentados (Dantas, 2001). As vertentes são predominantemente de retilíneas a côncavas ou escarpadas, com topos de cristas alinhadas, levemente arredondados, onde a amplitude topográfica pode ser superior a $400 \mathrm{~m}$. O domínio de morros é caracterizado por vertentes retilíneas e côncavas, com topos aguçados ou alinhados. Neste domínio há a sedimentação de colúvios e alúvios, além da amplitude topográfica variar de $100 \mathrm{~m}$ a $200 \mathrm{~m}$. O domínio de colinas é caracterizado por vertentes pouco dissecadas e forma convexa, sendo os topos arredondados ou alongados. Os desníveis altimétricos variam entre $20 \mathrm{~m}$ e $100 \mathrm{~m}$, ocorrendo, ainda, expressiva sedimentação de colúvios e alúvios. O domínio de planícies aluviais é caracterizado por desníveis entre $0 \mathrm{~m}$ e $20 \mathrm{~m}$, com gradientes extremamente suaves e convergentes em direção aos canaistronco, constituindo a área de deposição dos sedimentos provenientes de toda a bacia à montante. 


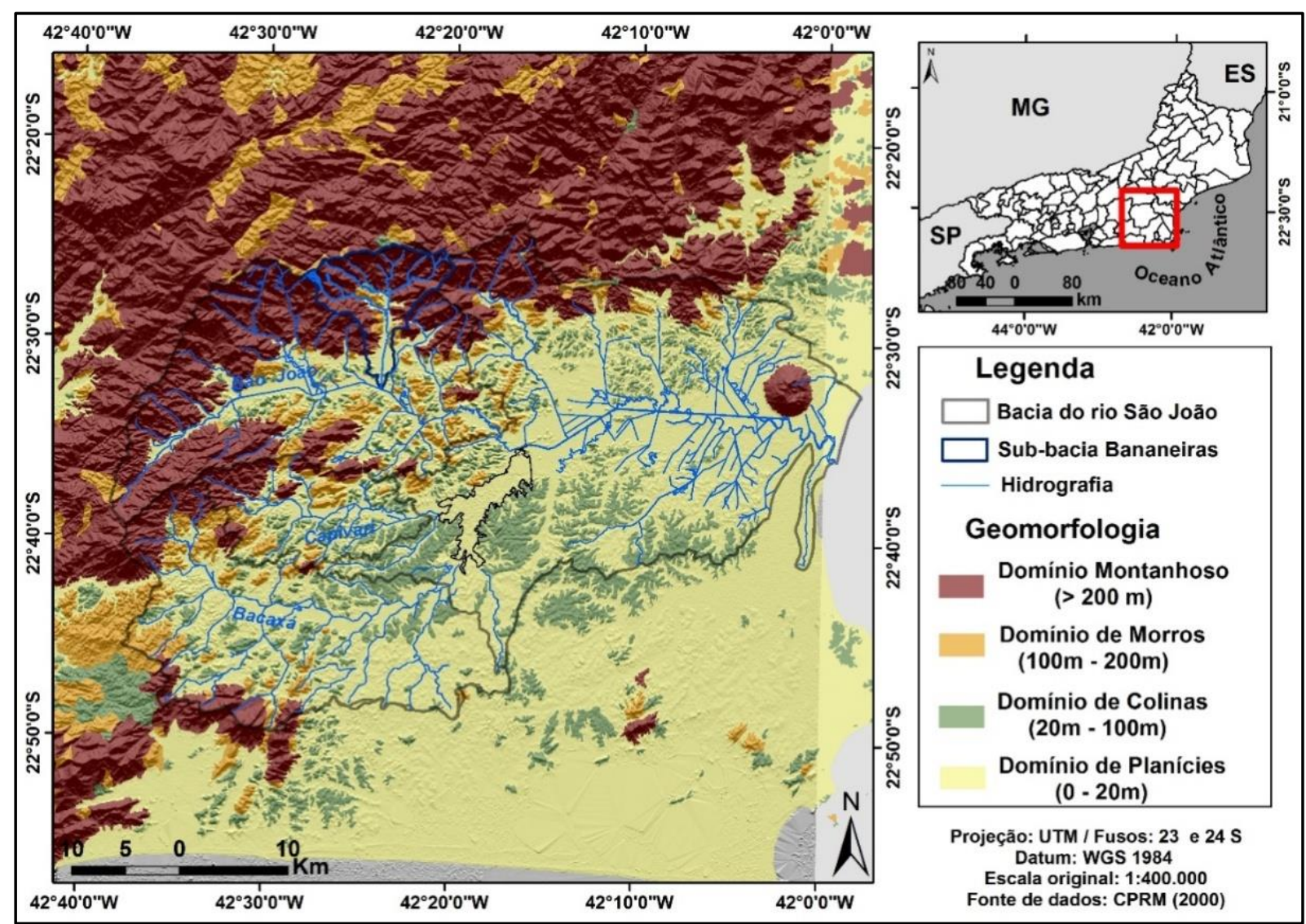

Figura 4 - Geomorfologia na bacia do rio São João, onde está inserida a bacia do rio Bananeiras.

A contraposição entre relevos mais acidentados e suaves na bacia pode ser observada através do perfil longitudinal do rio Bananeiras (Figura 5). No alto curso, o rio possui um desnivelamento altimétrico acentuado, de $450 \mathrm{~m}$ em cerca de $2,5 \mathrm{~km}$. O trecho seguinte, caracterizado como médio curso, apresenta declive mais suave, com confluências de grande aporte sedimentar dos tributários mais expressivos. No baixo curso fica evidente uma vasta planície fluvial com extensão de $10 \mathrm{~km}$ e desnível praticamente nulo (cerca de $20 \mathrm{~m}$ ).

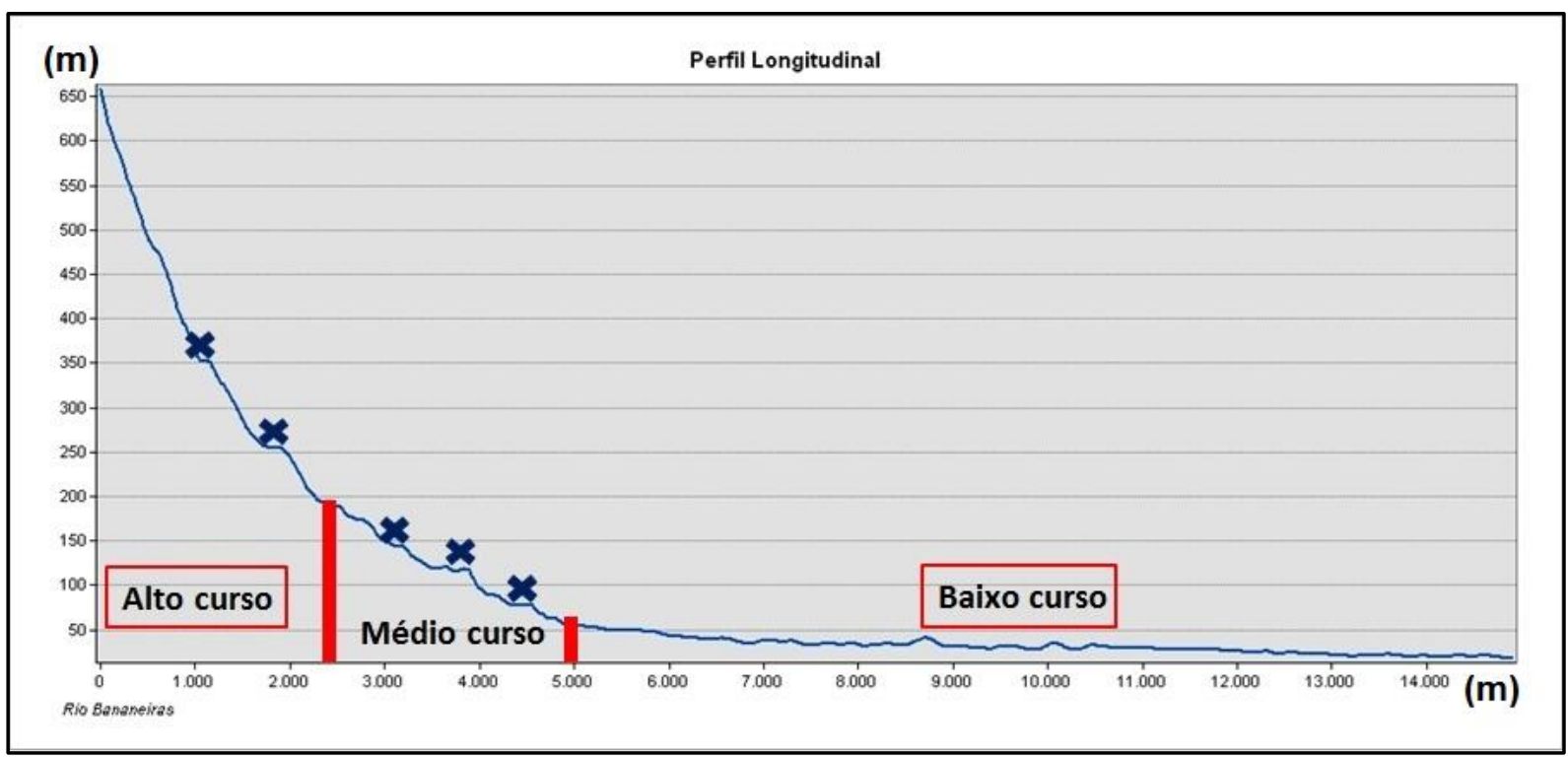

Figura 5 - Perfil longitudinal do rio Bananeiras. $\mathrm{O}$ " $\mathrm{x}$ " marca as confluências dos principais afluentes do rio Bananeiras. 
A região sudeste do Brasil é influenciada quase o ano todo pela Massa Tropical Atlântica (mtA), caracterizada pela predominância dos ventos de leste (Sant'Anna Neto, 2005). A forte radiação solar das latitudes tropicais e a grande umidade relativa, devido à intensa evaporação marítima, caracteriza a área como clima tropical quente úmido. As temperaturas médias para a região da bacia variam de $18^{\circ} \mathrm{C}$ a $24^{\circ} \mathrm{C}$, sendo influenciadas pela presença da Serra do Mar. O mês mais quente é fevereiro, cuja máxima pode chegar a $32^{\circ} \mathrm{C}$, enquanto alcança apenas $25,5^{\circ} \mathrm{C}$ em junho, que é o mês mais frio. No que se refere à média anual, os índices pluviométricos na região estão acima dos $2.000 \mathrm{~mm}$, situação apoiada pela proximidade com a Serra do Mar (Tabela 1).

Tabela 1 - Média anual dos índices pluviométricos na bacia do rio São João de 1968 a 2015.

\begin{tabular}{c|c}
\hline Estação & Precipitação anual (mm) \\
\hline Piller & 2288,08 \\
\hline Gaviões & 2283,87 \\
\hline Quartéis & 2351,80 \\
\hline
\end{tabular}

Fonte dos dados: CPRM/ANA.

Em relação às médias mensais, observa-se a existência de duas estações bem definidas, sendo uma úmida (novembro a abril) e outra seca (maio a outubro). $\mathrm{Na}$ estação úmida, a precipitação encontra-se acima dos $200 \mathrm{~mm}$ mensais, enquanto na estação seca os índices pluviométricos estão abaixo de $150 \mathrm{~mm}$ (Figura 6). Ao longo da série histórica (Figura 7) observa-se comportamento pluviométrico bastante parecido nas três estações, com alguns picos, tanto para mais (1983, 1994, 2004, 2005, 2008 e 2009) como para menos da média $(1970,1984,1997,2000,2012$ e 2014).

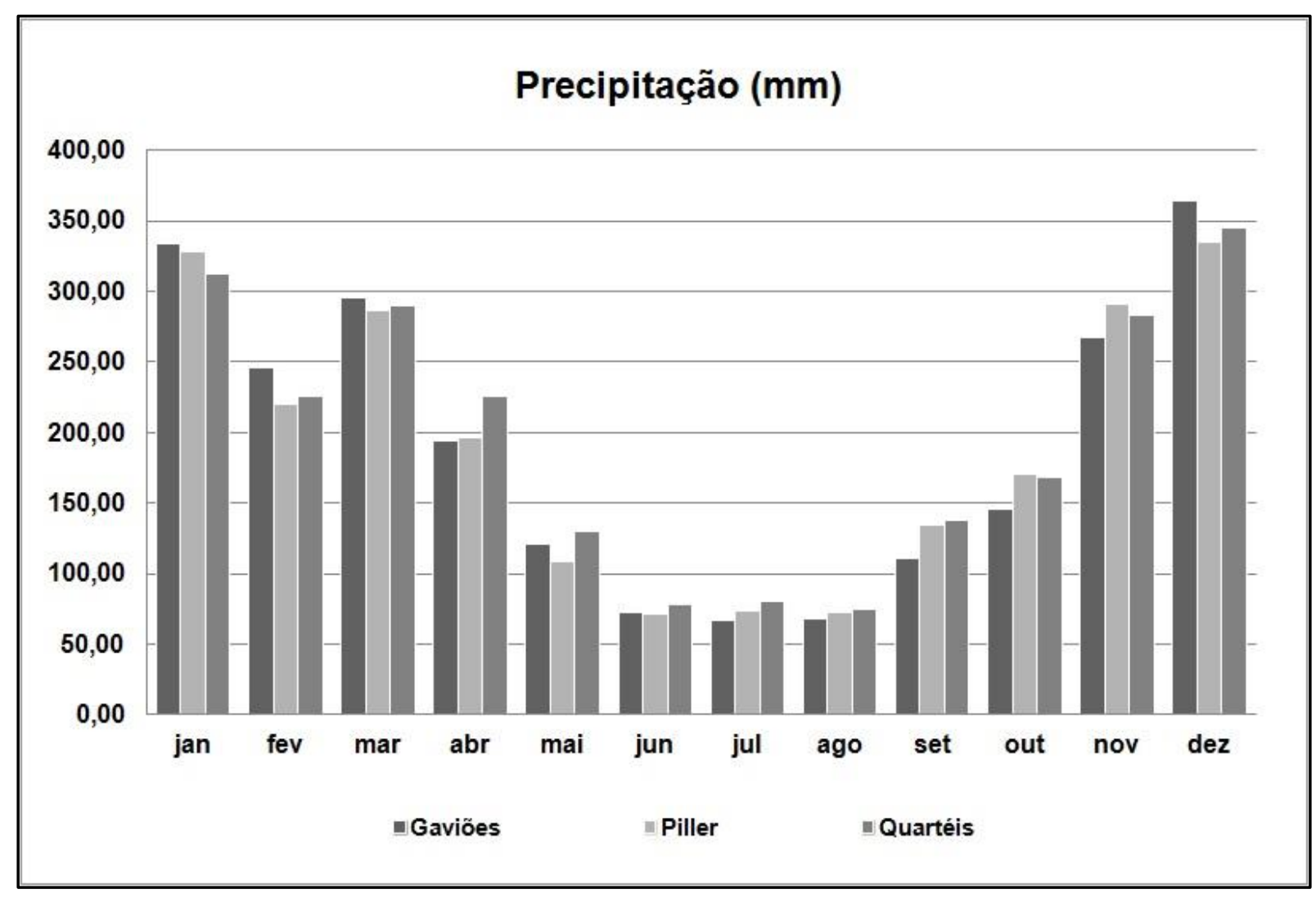

Figura 6 - Médias mensais da séria histórica (1968-2015). Fonte dos dados: CPRM/ANA. 


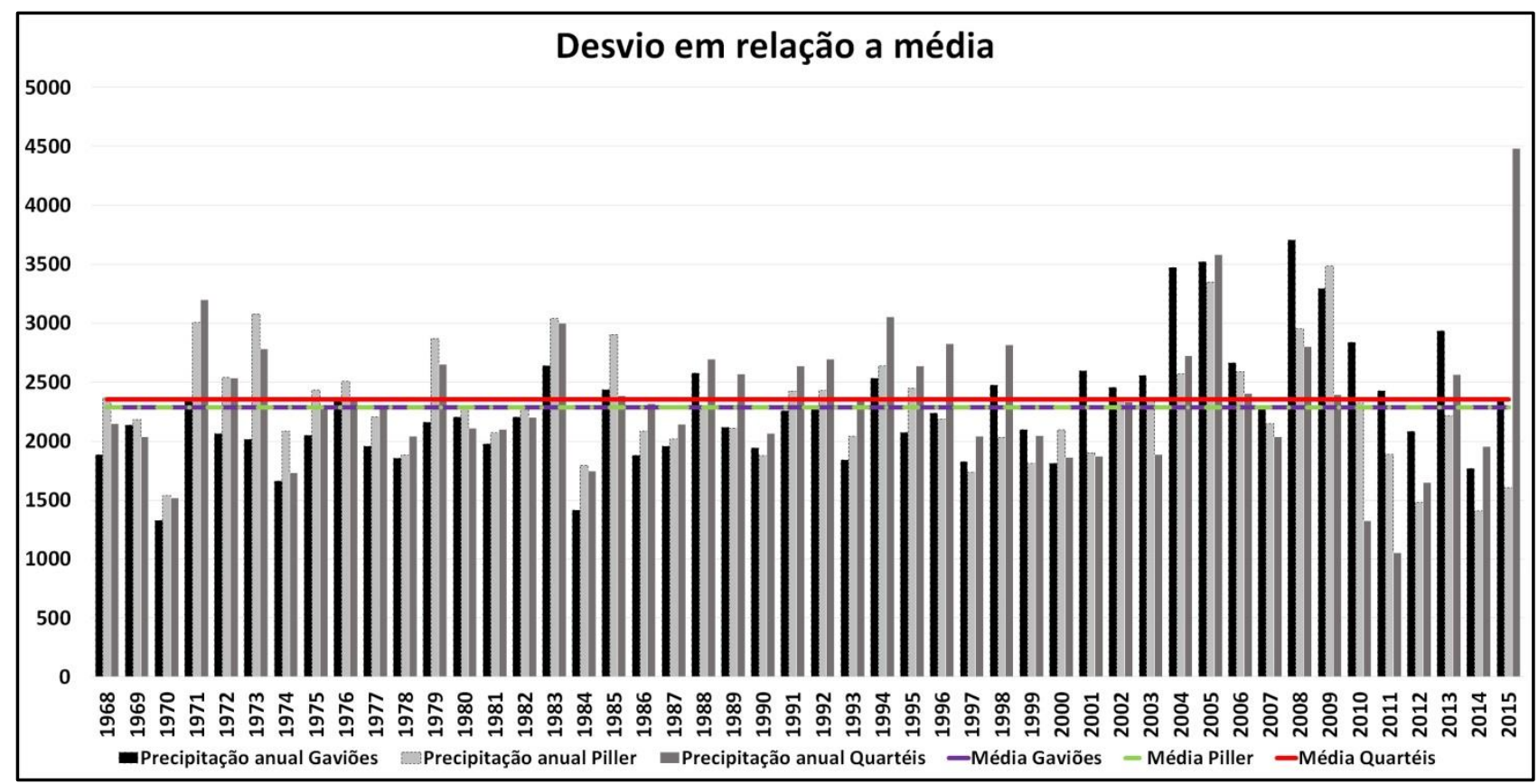

Figura 7 - Variações da precipitação em relação às médias nas estações ao longo da série histórica (19682015). Fonte dos dados: CPRM/ANA.

\section{Ocupação e uso da terra}

A bacia do rio Bananeiras está inserida no contexto hidrográfico do alto curso do rio São João, que integra o principal sistema fluvial contribuinte da represa de Juturnaíba, fundamental para o abastecimento de água para municípios da região dos Lagos, no estado do Rio de Janeiro. Por toda área de contribuição do rio São João é possível observar intervenções humanas, que vêm ocorrendo desde o período de colonização do Brasil (Quadro 1). O desmatamento de áreas de vegetação nativa para implantação de atividades agropastoris marcou o início da ocupação da bacia do rio São João (IBGE, 1959).

A ocupação antrópica na região promoveu o desmatamento principalmente nas planícies e encostas mais suaves, já que a declividade acentuada dificultou a ocupação nas áreas mais altas, fato que favoreceu a manutenção de remanescentes de cobertura florestal relacionada ao bioma Mata Atlântica (SEMADS, 2001).

Quadro 1 - Cronologia de intervenções realizadas.

\begin{tabular}{c|c}
\hline Período & Intervenção antrópica \\
\hline Século XVII & $\begin{array}{c}\text { Desmatamento e implantação das primeiras lavouras, inclusive café, } \\
\text { além do aterro de áreas alagadas pelos primeiros colonos. }\end{array}$ \\
\hline Século XIX & Instalação da Estrada de Ferro Leopoldina e consolidação de povoados \\
\hline Década de 1950 & $\begin{array}{c}\text { Primeiras retificações e dragagens na planície fluvial do rio São João e } \\
\text { afluentes para implantação de cultivo irrigado. }\end{array}$ \\
\hline Década de 1980 & $\begin{array}{c}\text { Construção da represa de Juturnaíba e início do extrativismo de areia } \\
\text { nos canais retificados. }\end{array}$ \\
\hline
\end{tabular}

Fontes: IBGE (1959); Cunha (1995).

A fim de impulsionar a produção agrícola na região, outras intervenções foram realizadas, tornando o município de Silva Jardim mais acessível. Na década de 1950, iniciaram-se obras de retificações na planície do rio, possibilitando a construção da rodovia federal BR-101.

Entre as décadas de 1950 e 1980, a referida bacia sofreu sucessivas obras de engenharia (retificação e dragagem) no canal fluvial visando 
drenar as áreas adjacentes para a implantação de cultivo irrigado (Cunha, 1995). Além disso, houve a construção da represa de Juturnaíba (1978-1984), ampliando em seis vezes a área de espelho d'água original de $5,56 \mathrm{~km}^{2}$, para abastecimento de água aos municípios próximos.

As retificações no canal principal e seus afluentes favoreceram uma série de alterações hidrodinâmicas (carga sedimentar do rio, vazão etc.), o que, segundo Cunha (1995), viabilizou a instalação de atividades extrativas de areia. A extração de areia aconteceu na bacia desde a década de 1970, à montante da represa de Juturnaíba, concentrando-se nos leitos dos rios São João, Pirineus e Bananeiras até o ano de 2002 (Oliveira, 2005).

Conforme mapeamento do INEA (2010), de forma geral, a bacia do rio São João apresenta usos de pastagem e agricultura consolidados, além de pequenos segmentos de ocupação urbana (Figura 8). Fica evidente ainda que os segmentos de floresta se encontram preservados, ocupando grande parte das encostas no alto curso do rio São João, na região da Reserva Biológica Poço das Antas e no morro de São João, próximo à foz do rio no oceano Atlântico. Além disso, observa-se a atividade de pastagem predominantemente nas encostas de relevo suave e em toda área de planície do rio São João, onde a cobertura vegetal é de gramíneas. Em alguns casos, encostas rebaixadas também sustentam segmentos de vegetação secundária em estágio inicial. As áreas de cultivos estão localizadas basicamente na planície fluvial à jusante da represa de Juturnaíba. Na bacia do Rio São João, as áreas urbanizadas consolidadas estão localizadas nas proximidades da foz, e no interior destacam-se apenas pequenos núcleos como de Casimiro de Abreu e Silva Jardim.

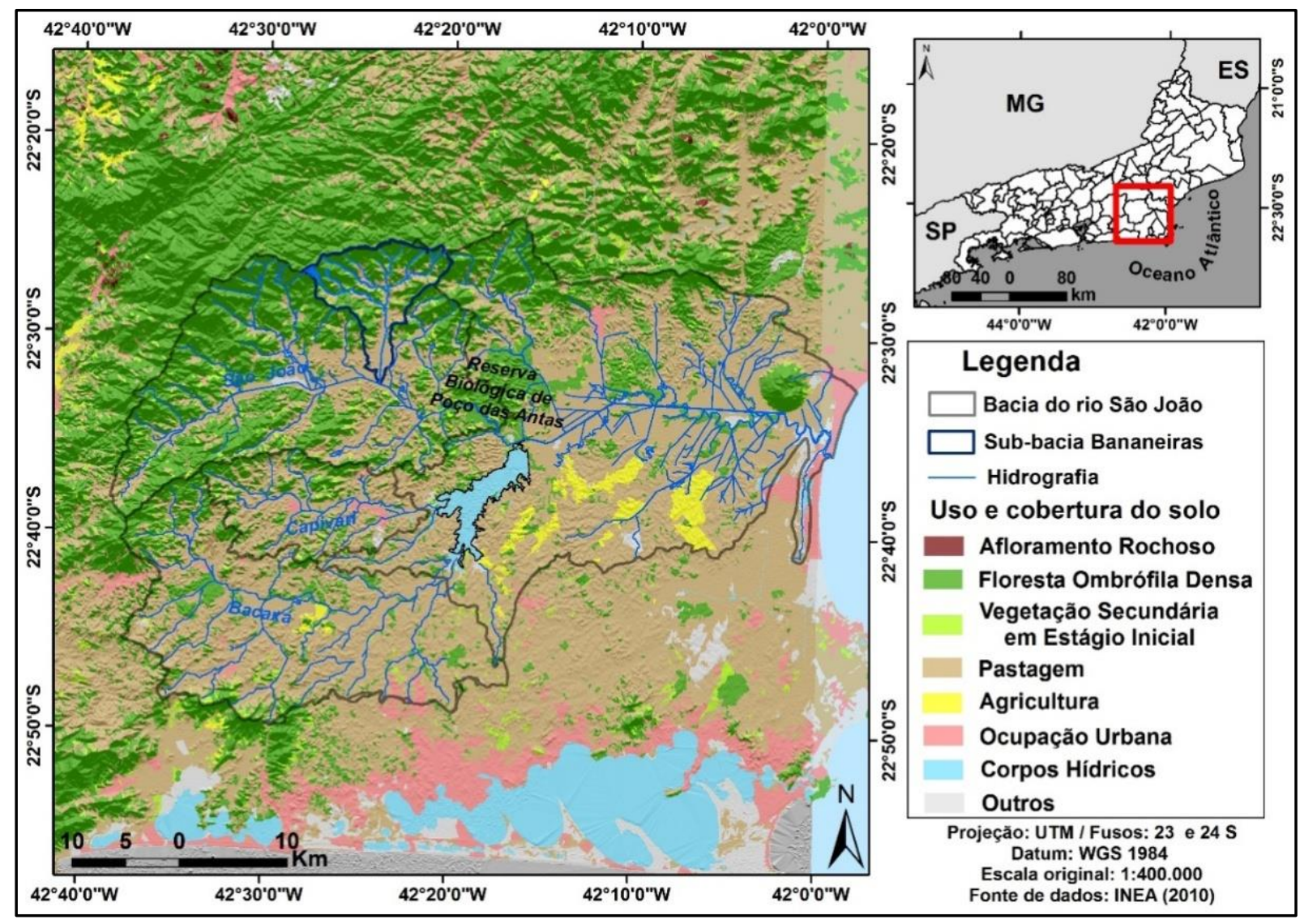

Figura 8 - Uso e cobertura da terra na bacia do rio São João, onde está inserida a bacia do rio Bananeiras.

\section{Estilos Fluviais}

No rio Bananeiras foram identificados cinco estilos de rios diferenciados em seu caráter e comportamento, permitindo, deste modo, a compreensão, de forma integrada, das formas e processos que caracterizam cada um deles (Figura 9; Tabela 2). Dentre os estilos identificados predominam os vales confinados e não confinados, uma vez que o rio Bananeiras não apresentou nenhum trecho característico de vale parcialmente confinado. A configuração e o confinamento do vale são controles primários sobre o caráter e o comportamento do rio, possibilitando diferentes 
habilidades para ajustar a morfologia do canal, a planificação e a constituição de unidades geomorfológicas (Montgomery, 1999; Brierley e Fryirs, 2005). Assim, observam-se diferentes comportamentos dos estilos identificados no rio Bananeiras em função da influência da configuração do vale.

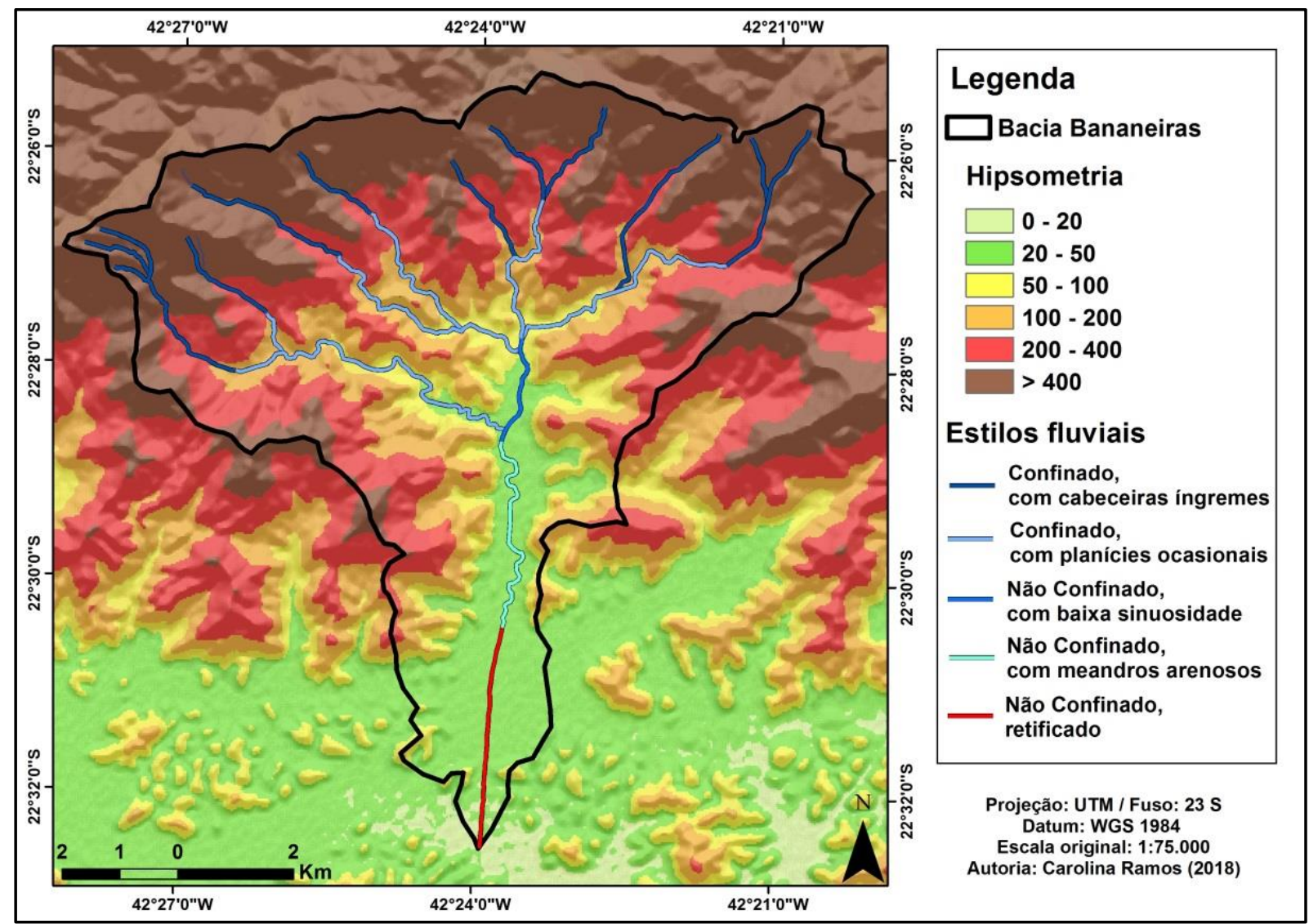

Figura 9 - Distribuição espacial dos estilos fluviais na bacia do rio Bananeiras.

A região do domínio montanhoso é ocupada predominantemente pelo estilo de rio confinado com cabeceiras íngremes, onde a alta energia tem potencial erosivo significativo. Nesse estilo a altitude do leito fluvial é de $400 \mathrm{~m}$ em algumas localidades e as declividades são acentuadas (> 45\%), concedendo baixo potencial para o armazenamento de sedimento. O desnível entre as encostas adjacentes e o fundo de vale pode ser superior a $200 \mathrm{~m}$, evidenciando o confinamento do vale. Esse estilo fluvial apresenta leito formado por cascalho, blocos, matacões, sendo as margens ocupadas por cobertura vegetal densa. Há a formação de cachoeiras, sequências de piscinas, cascatas e características de riffle-pool devido à presença de rochedos e pedregulhos no canal (Figura 10). Tais características conferem certa estabilidade do canal, ou seja, capacidade limitada para o ajuste deste.

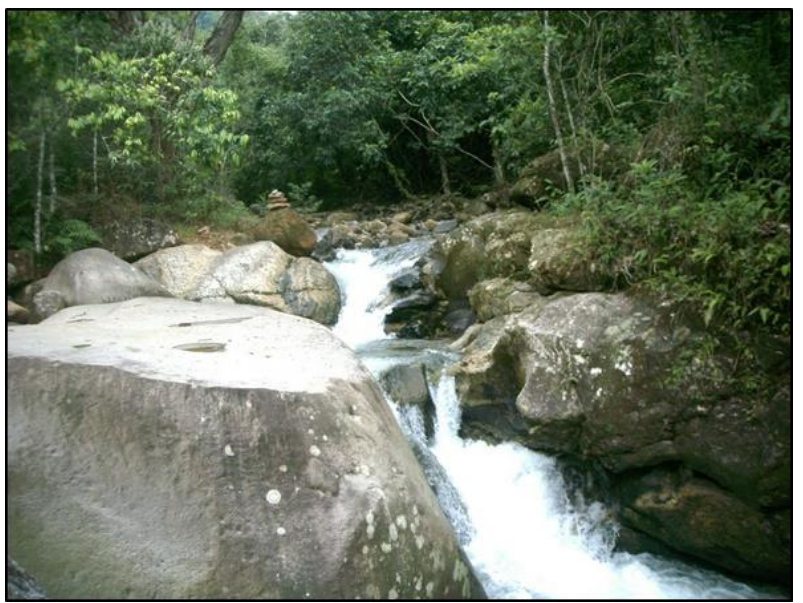

Figura 10 - Leito rochoso no estilo fluvial confinado com cabeceiras íngremes. Fonte da imagem: Panoramio Google Earth Pro (2016). 
Revista Brasileira de Geografia Física v.12, n.3. (2019) 895-912. DOI: 10.268484/ rbgf.v12.3.p895-912

Tabela 2 - Atributos distintivos dos estilos fluviais na bacia do rio Bananeiras.

\begin{tabular}{|c|c|c|c|c|c|c|c|}
\hline \multirow{2}{*}{\multicolumn{2}{|c|}{ Estilos Fluviais }} & \multirow{3}{*}{$\begin{array}{c}\text { Vale } \\
\text { Confinado }\end{array}$} & \multirow{3}{*}{$\begin{array}{c}\begin{array}{c}\text { Uso e/ou } \\
\text { cobertura } \\
\text { da terra }\end{array} \\
\begin{array}{c}\text { Floresta } \\
\text { ombrófila } \\
\text { densa }\end{array}\end{array}$} & \multirow{3}{*}{$\begin{array}{c}\text { Unidade de } \\
\text { relevo } \\
\text { Montanhoso }\end{array}$} & \multicolumn{2}{|c|}{ Caráter do rio } & \multirow{3}{*}{$\begin{array}{l}\text { Comportamento do rio } \\
\text { anal com alto controle litológico, } \\
\text { onde as margens encontram-se } \\
\text { estáticas no vale confinado. }\end{array}$} \\
\hline & & & & & \multirow{2}{*}{$\begin{array}{l}\text { Forma em planta } \\
\text { Canal único, com alto } \\
\text { declive e sem planície. }\end{array}$} & \multirow{2}{*}{$\begin{array}{c}\begin{array}{c}\text { Unidades } \\
\text { geomorfológicas }\end{array} \\
\text { Leito rochoso }\end{array}$} & \\
\hline 1 & $\begin{array}{l}\text { Confinado, } \\
\text { com } \\
\text { cabeceiras } \\
\text { íngremes. }\end{array}$ & & & & & & \\
\hline 2 & $\begin{array}{l}\text { Confinado, } \\
\text { com planícies } \\
\text { ocasionais }\end{array}$ & Confinado & $\begin{array}{l}\text { Vegetação } \\
\text { secundária } \\
\text { ou } \\
\text { pastagem }\end{array}$ & $\begin{array}{l}\text { Morros e } \\
\text { Colinas }\end{array}$ & $\begin{array}{l}\text { Canal único, inserido em } \\
\text { vales encaixados e } \\
\text { sinuosos, com ocorrência } \\
\text { de alvéolos fluviais } \\
\text { descontínuos. } \\
\end{array}$ & Leito rochoso & $\begin{array}{l}\text { Canal situado em vale estreito } \\
\text { apresentando alvéolos fluviais em } \\
\text { sua extensão. }\end{array}$ \\
\hline 3 & $\begin{array}{l}\text { Não } \\
\text { confinado, } \\
\text { com baixa } \\
\text { sinuosidade }\end{array}$ & $\begin{array}{c}\text { Não } \\
\text { confinado }\end{array}$ & Pastagem & Planície & $\begin{array}{l}\text { Canal único com } \\
\text { sinuosidade baixa a } \\
\text { moderada }\end{array}$ & $\begin{array}{l}\text { Ilhas e barras } \\
\text { laterais e } \\
\text { longitudinais }\end{array}$ & $\begin{array}{c}\text { Canal com desenvolvimento de } \\
\text { planície de inundação contínua. A } \\
\text { sinuosidade do vale já em } \\
\text { ambiente plano condiciona o } \\
\text { amortecimento do fluxo e unidades } \\
\text { geomorfológicas como ilhas e } \\
\text { barras. }\end{array}$ \\
\hline 4 & $\begin{array}{c}\text { Não } \\
\text { confinado, } \\
\text { com meandros } \\
\text { arenosos }\end{array}$ & $\begin{array}{c}\text { Não } \\
\text { confinado }\end{array}$ & Pastagem & Planície & $\begin{array}{l}\text { Canal único com } \\
\text { desenvolvimento de } \\
\text { meandros }\end{array}$ & $\begin{array}{l}\text { Barras em pontal, } \\
\text { meandros e terraços }\end{array}$ & $\begin{array}{l}\text { Canal com margens ativas } \\
\text { evidenciando processos de erosão } \\
\text { em larga escala nas margens } \\
\text { côncavas e migração lateral do } \\
\text { leito. Nas margens convexas } \\
\text { observam-se barras de pontal } \\
\text { formadas de material de areia } \\
\text { grossa e seixos. }\end{array}$ \\
\hline 5 & $\begin{array}{l}\text { Não } \\
\text { Confinado, } \\
\text { retificado }\end{array}$ & $\begin{array}{c}\text { Não } \\
\text { confinado }\end{array}$ & Pastagem & Planície & $\begin{array}{l}\text { Canal único, retificado e } \\
\text { ocorrência de sinuosidade } \\
\text { baixa ao longo da calha. }\end{array}$ & $\begin{array}{c}\text { Calha retilínea com } \\
\text { barras incipientes }\end{array}$ & $\begin{array}{l}\text { A retificação do leito resultou no } \\
\text { encurtamento do cumprimento do } \\
\text { canal favorecendo a remoção de } \\
\text { grande maioria das feições } \\
\text { geomorfológicas no canal. }\end{array}$ \\
\hline
\end{tabular}


Seguindo à jusante, o rio Bananeiras apresenta localidades onde, ocasionalmente, seu vale confinado se alarga, formando pequenas planícies de inundação, o que caracteriza o segundo estilo identificado. $\mathrm{O}$ estilo fluvial confinado com planícies de inundação ocasionais ocupa relevo de morros e colinas, e possui uma altitude média de $152 \mathrm{~m}$, onde os declives não se apresentam acentuados. O curso d'água nesse estilo possui sinuosidade que varia de moderada a alta em algumas regiões, confinado lateralmente pelo vale. Contudo, possui alguns alvéolos fluviais que ocorrem em lados alternados do canal, correspondendo a menos de $10 \%$ do cumprimento do estilo (Figura 11). Além disso, apresenta um leito predominantemente rochoso, com formação de cachoeiras e pequenas cascatas. No entanto, nos ocasionais alargamentos do vale sedimentos podem ser depositados. $\mathrm{Na}$ área deste estilo fluvial verifica-se vegetação secundária ou pastagem.

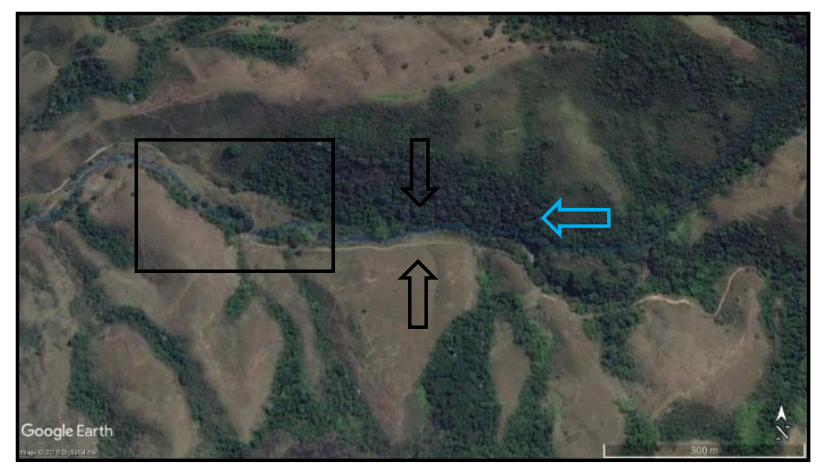

Figura 11 - Estilo fluvial confinado com planícies de inundação ocasionais, onde se observa trecho confinado (setas pretas) e alvéolo fluvial à jusante (área no retângulo). Fonte da imagem: Google Earth Pro (2016).

Considerando a perspectiva de condição geomorfológica, os estilos fluviais que se desenvolvem em ambientes confinados mostramse mais resilientes a eventos intensos de descarga e aporte sedimentar, pois o leito rochoso e o confinamento do vale impedem ou dificultam ajustes laterais do canal. Além disso, apresentam elevada capacidade de transferir sedimentos para jusante (Fryirs e Brierley, 2001; Hooke, 2003; Fryirs et al., 2016).

$O$ estilo não confinado com baixa sinuosidade é caracterizado por ser o início da zona de armazenamento de sedimentos no canal do

\footnotetext{
1 Nesse trabalho optou-se por chamar de paleocanal aqueles canais que encontram-se abandonados e localizados no terraço fluvial, como forma de diferenciá-los dos canais abandonados na atual planície
}

rio Bananeiras, ao contrário dos estilos à montante, onde predominavam os processos de erosão. A configuração do vale também permite o desenvolvimento de planície de inundação contínua e a diminuição da velocidade do fluxo favorece a criação de ambientes de deposição (barras e ilhas) ao longo do trecho (Figura 12). Cabe ressaltar ainda que esse estilo recebe a carga sedimentar de vários rios afluentes à montante. Esse material, com textura predominante arenosa, mostra-se muito propenso a ser retrabalhado durante eventos intensos de precipitação e consequente aumento de vazão, sendo mobilizado para os estilos à jusante.

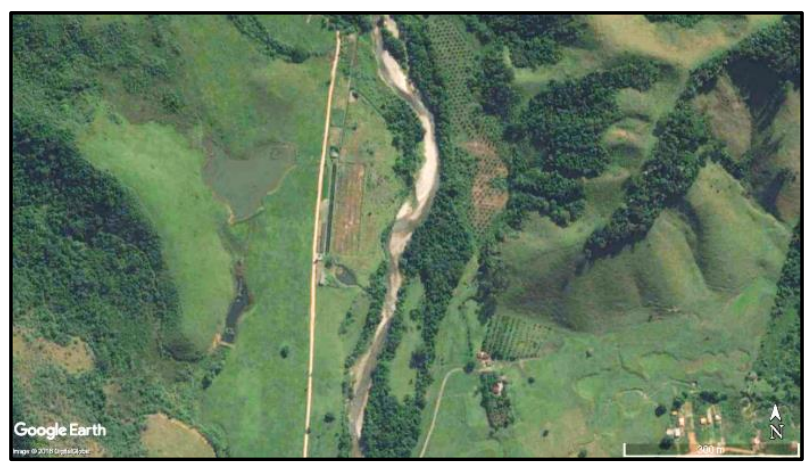

Figura 12 - Estilo fluvial não confinado com baixa sinuosidade, apresentando ambientes de deposição ao longo do trecho. Fonte da imagem: Google Earth Pro (2016).

\section{O estilo não confinado com meandros arenosos também ocupa o domínio} geomorfológico de planícies cuja declividade é praticamente nula. Dado o baixo gradiente, o substrato arenoso e o espaço para ajuste lateral, a sinuosidade nesse estilo aumenta, possibilitando a formação dos meandros ativos sobre depósitos arenosos (Figura 13). Ao longo do canal são observadas extensas barras de pontal nas margens convexas dos meandros, formadas pela deposição de material arenoso, enquanto as margens côncavas são altamente suscetíveis à ação erosiva, principalmente durante os eventos de precipitação intensa e aumento de vazão. Nesse estilo de rio já é possível observar a presença de terraço fluvial sob atuação de processos erosivos em sua base, e, em alguns casos, paleocanais ${ }^{1}$ evidenciando onde cursava o rio Bananeiras em tempos pretéritos (Figura 14).

de inundação, que são aqui chamados de meandros abandonados. 


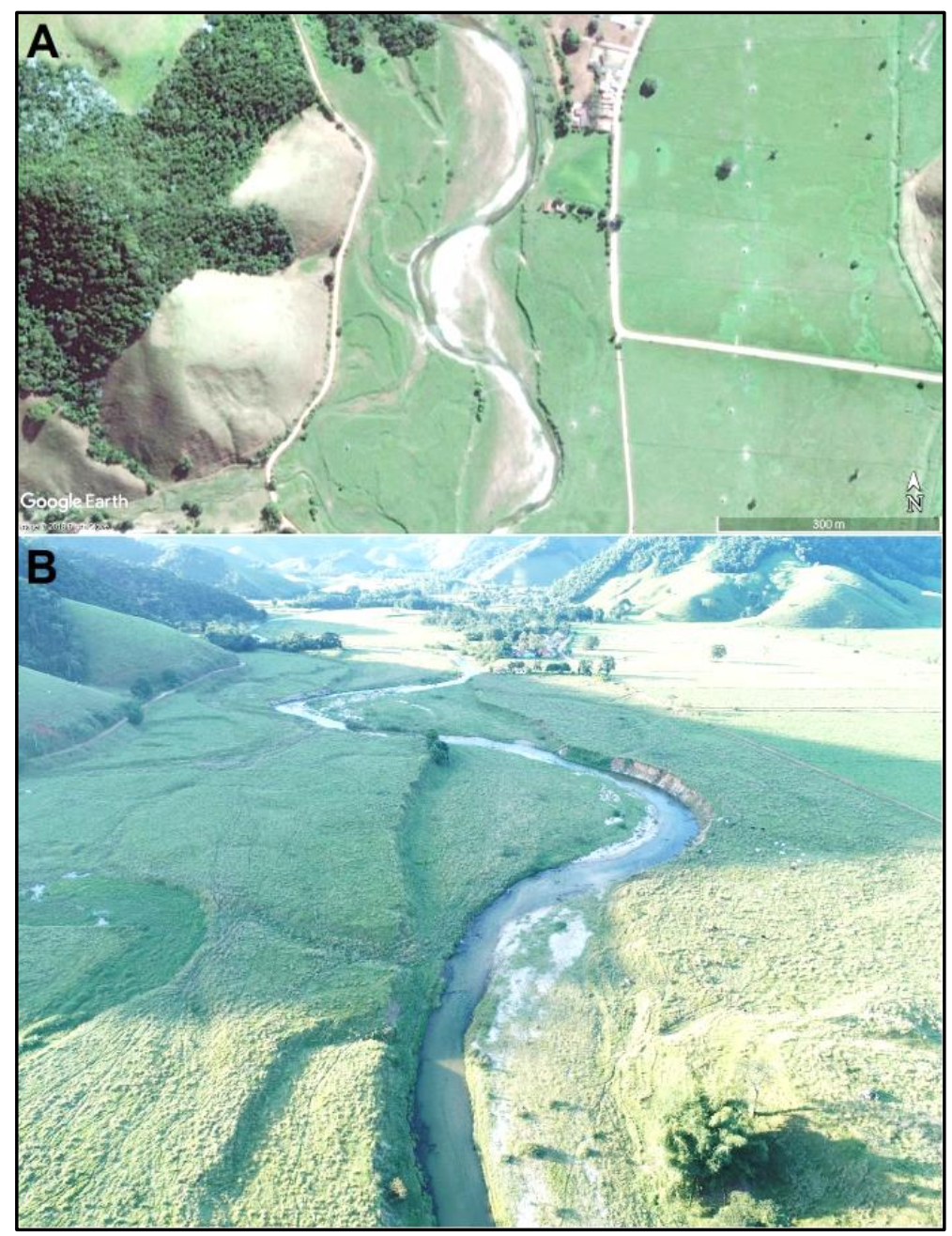

Figura 13 - Estilo não confinado com meandros em substrato arenoso. A: Meandros atuais e vestígios de traçados pretéritos do rio Bananeiras (paleocanais). B: Meandros do atual canal e paleocanais presentes no terraço fluvial. Fonte das imagens: Google Earth Pro (2016); Prof. Guilherme Fernandez (2018).

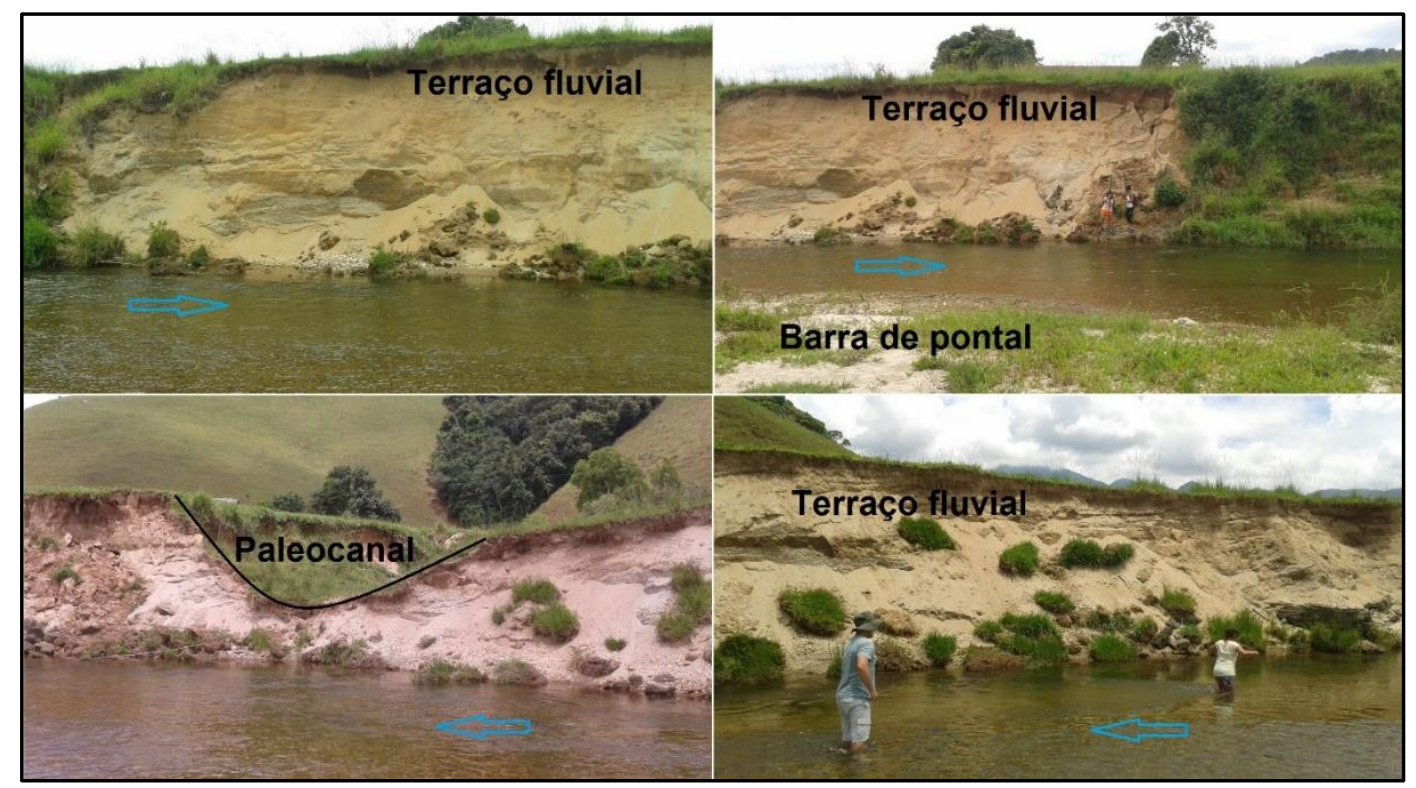

Figura 14 - Feições geomorfológicas observadas no estilo fluvial não confinado com meandros em substrato arenoso. Fonte das imagens: Guilherme Fernandez (2017). 
Perfis topográficos realizados nessa localidade (Figura 15) destacam condições representadas na figura anterior. Por meio dos perfis topográficos 1 e 2 da figura 15 é possível perceber que os terraços presentes na região têm aproximadamente $6 \mathrm{~m}$ de altura. Além disso, tais perfis mostram que o rio possui largura aproximada de $15 \mathrm{~m}$ neste trecho. A barra de pontal localizada na margem esquerda do canal possui $75 \mathrm{~m}$ de extensão, conforme apresentado no perfil 1. $\mathrm{O}$ paleocanal (borda A do perfil 1) presente no terraço da margem direita apresenta largura em torno de 15 $\mathrm{m}$, conforme demonstrado no perfil transversal 3. Por outro lado, esse perfil também apresenta outro paleocanal, que seria na verdade uma curva de meandro abandonado de aproximadamente $58 \mathrm{~m}$ de extensão.

As feições expostas nos perfis topográficos evidenciam uma condição geomorfológica de maior sensibilidade aos canais em ambientes não confinados, relacionada à ocorrência de ajuste lateral e vertical (Brierley e Fryirs, 2000; Brierley et al., 2006). Neste contexto, os estilos fluviais presentes no domínio de planície com sedimentação arenosa estão mais susceptíveis a ajustes morfológicos (Fryirs e Brierley, 2001; Brierley e Fryirs, 2005; Fryirs et al., 2007). No rio Bananeiras esses ajustes podem ocorrer em função da erosão das margens, como também pelo retrabalhamento de feições deposicionais arenosas no leito.

Além disso, nas regiões mais baixas da bacia (médio e baixo cursos), grande parte da cobertura vegetal original foi substituída por pastagens (vegetação de gramíneas), que reduz a fixação de sedimentos, favorecendo ao aumento do processo de erosão das margens. 


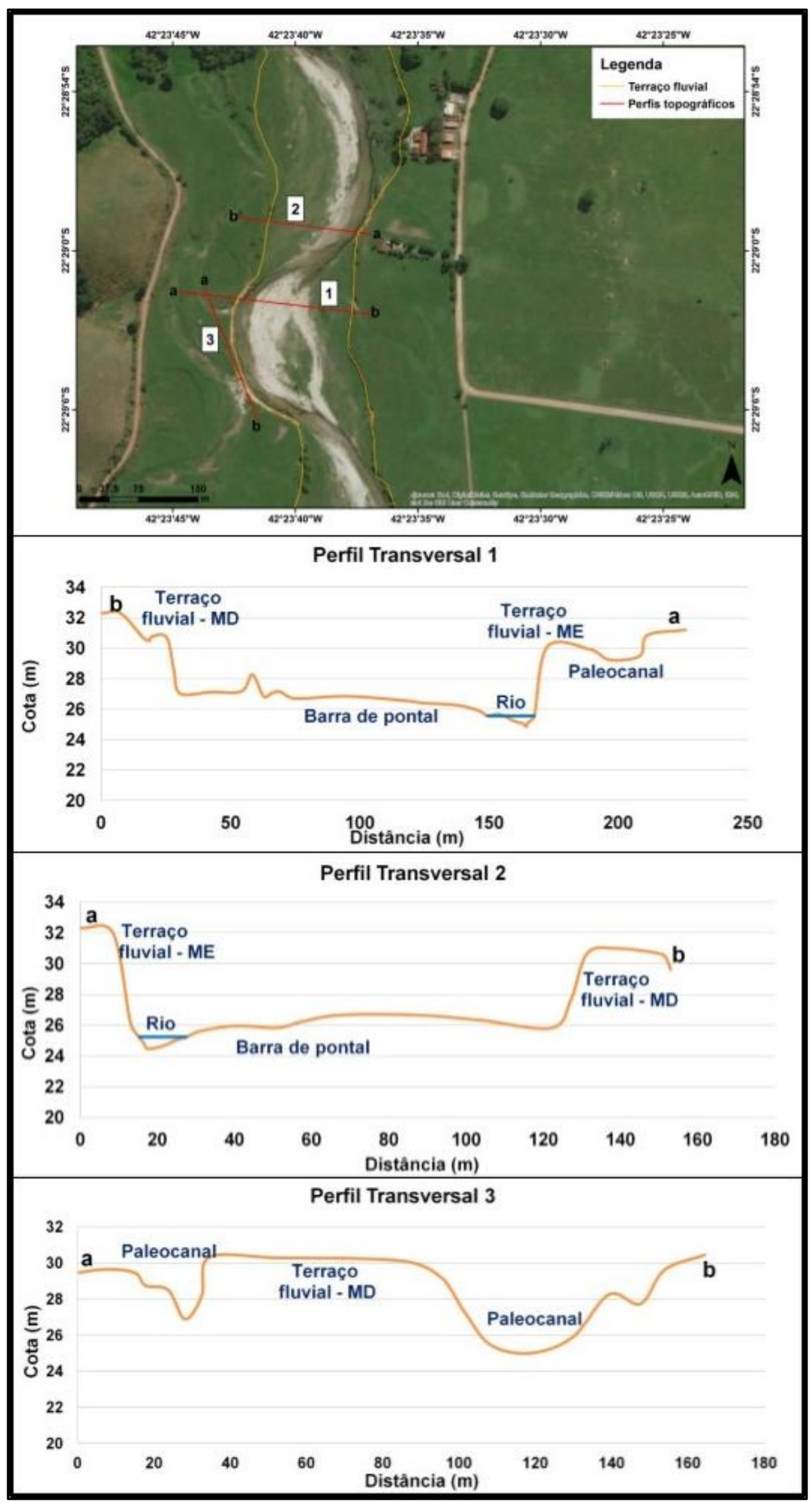

Figura 15 - Perfis topográficos destacando as feições presentes no estilo fluvial não confinado com meandros arenosos. MD - margem direita, ME - margem esquerda. 
O estilo fluvial não confinado retificado é reflexo das atividades humanas na bacia do rio Bananeiras. Esse trecho do canal foi retificado no passado (decorrentes de obras realizadas até os anos de 1970) para drenar a planície onde corriam canais meândricos e possibilitar o desenvolvimento de agricultura e pecuária. Assim, o estilo apresentado possui canal retilíneo com leito arenoso e margens simétricas com poucas barras laterais, evidentes no canal principalmente no período seco (Figura 16 - A, set./2016). Observase uma extensa planície fluvial ocupando um vale não confinado, onde é possível observar a existência de meandros abandonados, na maioria das vezes já preencidos por vegetação, e que podem ser inundados no período úmido (Figura 16 - A, fev./2016).

As alterações em seu traçado original e na geometria de seu canal por meio de obras de retificação e aprofundamento intensificou, durante a década de 1980, a erosão nas regiões à montante da retificação (Cunha, 1995). O aprofundamento da calha fluvial desencadeou inúmeros efeitos sobre a hidrodinâmica do rio, entre estes o aumento da velocidade do escoamento fazendo com que o rio
Bananeiras tivesse a competência de transferir sedimentos arenosos até a foz, fato analisado por Oliveira (2005). Em função disso, esse estilo tem a capacidade de transferir grandes quantidades de sedimentos, formando uma barra de até $128 \mathrm{~m}$ de extensão na confluência com o rio São João (Figura 16 - B). Cabe ressaltar que essa barra fica evidente durante o período seco na região, considerando que no perído úmido o rio São João pode apresentar capacidade suficiente para carrear todo sedimento. Tal situação também foi observada no rio Macaé, bacia vizinha ao rio São João (Marçal, 2013).

Atualmente, o trecho retificado do rio Bananeiras apresenta barras laterais arenosas, algumas tendendo a se fixar às margens, caracterizando a sinuosidade do talvegue do rio. Deste modo, o estilo fluvial não confinado retificado possui uma condição geomorfológica de baixa sensibilidade, mas buscando ajustar sua dinâmica às características locais de reduzida declividade, significativo aporte sedimentar e pluviosidade expressiva no verão.

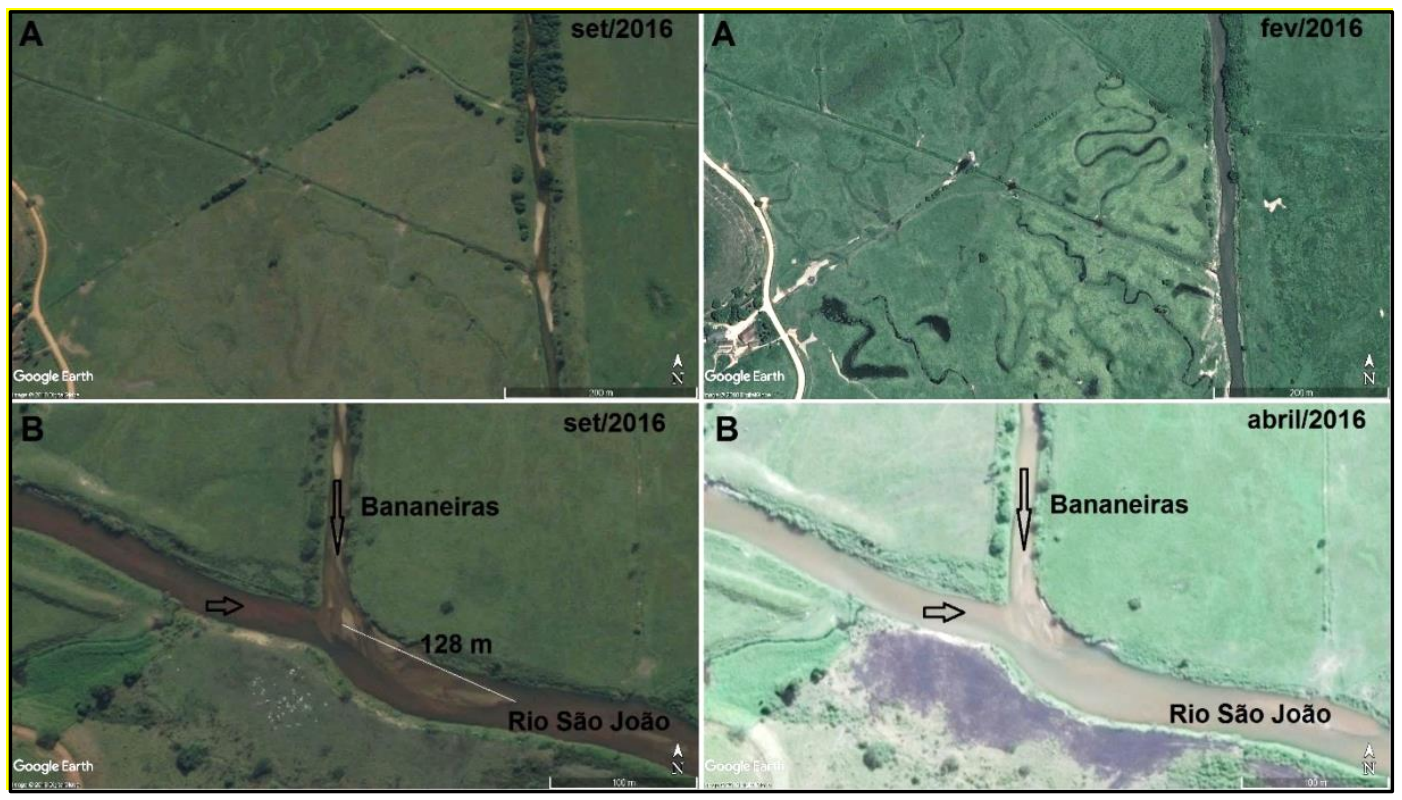

Figura 16 - Características presentes no estilo fluvial Não confinado retificado. Fonte da imagem: Google Earth Pro (2016).

\section{Conclusão}

A aplicação da metodologia de classificação de estilos fluviais na bacia hidrográfica do rio Bananeiras (Silva Jardim, RJ) conduziu à identificação e caracterização de cinco estilos fluviais. Para tanto, os segmentos de canal foram classificados de acordo com condições específicas de cada trecho, levando em consideração também a interferência dos controles 
regionais (geologia, relevo, clima, uso da terra), o que permitiu conhecer o caráter e comportamentos distintos no sistema hidrográfico analisado.

Os estilos fluviais confinado com cabeceiras íngremes e confinado com planícies de inundação ocasionais ocorrem sob domínio de relevo montanhoso e de morros, que possuem declividades bem elevadas. $\mathrm{O}$ grau de confinamento do vale, o leito rochoso do canal e a densa cobertura florestal configuram uma condição de estabilidade geomorfológica a estes estilos.

Os outros três estilos fluviais (não confinado com baixa sinuosidade, não confinado com meandros arenosos e não confinado retificado) ocorrem ao longo do domínio de planície, onde o rio não está confinado lateralmente. Cada um desses trechos apresenta características morfodinâmicas próprias, sendo o estilo não confinado com meandros arenosos considerado o mais sensível devido aos ajustes rápidos e contínuos. O seu dinamismo é verificado pela persistência do padrão meândrico impresso na planície fluvial (meandros abandonados e paleocanais sobre o terraço aluvial), assim como os meandros ativos. Neste último caso, a dinâmica de evolução do padrão meândrico continua construindo barras de pontal na parte convexa e erodindo as margens côncavas do canal.

Por outro lado, o estilo não confinado retificado apresenta barras arenosas laterais alternadas, evidenciando a sinuosidade do talvegue do rio. Isto indica o ajuste do canal à descarga e ao aporte sedimentar, mas não necessariamente uma adequação à baixa declividade e ao não confinamento. As obras de retificação neste trecho representam uma mudança tão intensa que exige um tempo de recuperação às condições originais meândricas extremamente longo, configurando uma condição geomorfológica de baixa sensibilidade.

De forma geral, verifica-se que a diversidade de comportamento refletida pelos cinco estilos fluviais identificados está intrinsecamente relacionada com os controles regionais, especialmente os contrastes observados no relevo (domínio montanhoso versus domínio de planície) e no uso e cobertura da terra (cobertura florestal versus uso agropecuário). Estes dois controles determinaram a caracterização dos estilos confinados e não confinados, além das diferentes condições geomorfológicas de cada estilo fluvial.

Os resultados encontrados nessa pesquisa apontam para a necessidade de uma avaliação mais aprofundada desses ajustes morfológicos, no sentido de melhor entender a dinâmica fluvial do rio Bananeiras. Deste modo, estratégias adequadas de planejamento e gestão do sistema fluvial podem ser melhor definidas.

\section{Agradecimentos}

Agradecemos ao Laboratório de Geografia Física (Lagef - UFF), em especial aos professores Dr. Guilherme Borges Fernandez e Dra. Thaís Baptista da Rocha, pelo apoio dado durante o desenvolvimento da dissertação de mestrado, defendida em 2018, e que deu origem a este artigo. Agradecemos também ao Conselho Nacional de Desenvolvimento Científico e Tecnológico (CNPq) pelo auxílio financeiro concedido.

\section{Referências}

Agência, A. N. A. (2017). Nacional de Águas. Disponível em: http://www3.ana.gov.br/. Acesso em. , 20, [Google Scholar]

Brierley, G. J., Fryirs, K. A., Boulton, A., \& Cullum, C. (2008). Working with change: the importance of evolutionary perspectives in framing the trajectory of river adjustment. In: River Futures: An Integrative Scientific Approach to River Repair. Society for Ecological Restoration International, Island, 65-84. [Google Scholar]

Brierley, G. J., Fryirs, K. A., \& Jain, V. (2006). Landscape connectivity: The geographic basis of geomorphic applications. Area, 38(2), 165-174. [Google $\underline{\text { Scholar }}$

Brierley, G., Fryirs, K., Outhet, D., \& Massey, C. (2002). Application of the River Styles framework as a basis for river management in. New South Wales, Australia. Applied Geography, 22, 91-122. [Google Scholar]

Brierley, G. J., \& Fryirs, K. A. (2005). Geomorphology and River Management: Applications of the River Styles Framework. Oxford, UK: Blackwell Publishing. [Google Scholar]

Cunha, S. B. (1995). Impactos das obras de engenharia sobre o ambiente biofísico da bacia do rio São João. Lisboa: Tese de Doutorado do Programa de Pós-Graduação em Geografia da Universidade de. Lisboa, 415p. [Google Scholar] 
Dantas, M. E. (2001). Estudo geoambiental do Estado do Rio de Janeiro. CPRM-Serviço Geológico do. Brasil, 19, [Google Scholar]

Frissell, C. A., Liss, W. J., Warren, C. E., \& Hurley, M. D. (1986). A hierarchical framework for stream habitat classification: viewing streams in a watershed context. Environmental management, 10(2), 199-214. [Google Scholar]

Fryirs, K. A., \& Brierley, G. J. (2001). Variability in sediment delivery and storage along river courses in Bega catchment, NSW, Australia: implications for geomorphic river recovery. Geomorphology, 38, 237 265. [Google Scholar]

Fryirs, K. A., Brierley, G. J., Preston, N. J., \& Spencer, J. (2007). Catchment-scale (dis)connectivity in sediment flux in the upper Hunter catchment. New South Wales, Austrália. Geomorphology, 84, 297316. [Google Scholar]

Instituto, I. B. G. E. (1959). Brasileiro de Geografia e Estatística, Enciclopédia dos Municípios brasileiros. Rio de Janeiro: IBGE, 724, [Google Scholar]

Instituto, I. N. E. A. (2018). Estadual do Ambiente (RJ). INEA. Disponível em: http://www.inea.rj.gov.br/Portal/MegaDrop Down/Monitoramento/Coberturavegetaleuso daterra/index.htm\&lang $=$ Acesso em. , 20, [Google Scholar

Kleina, M., De_Paula, E. V., \& Santos, L. J. C. (2014). Análise comparativa dos Estilos Fluviais do rio Sagrado (Morretes/PR) para os anos de 2006 e 2011. Revista Geografar, v. 9, 1, 27-44. [Google Scholar]

Lima, R. N., \& Marçal, M. S. (2013). Avaliação da Condição Geomorfológica da Bacia do rio Macaé-RJ a partir da Metodologia de Classificação dos Estilos Fluviais. Revista Brasileira de Geomorfologia, 14(2), 171179. [Google Scholar]
Marçal, M. S., \& Geomorfologia v 14, (2013). Análise das mudanças morfológicas em seções transversais ao rio Macaé-RJ. Revista Brasileira de. , 1, 59-68. [Google Scholar]

Marçal, M. S., Brierley, G., \& Lima, R. (2017). Using geomorphic understanding of catchment-scale process relationships to support the management of river futures. Macaé Basin, Brazil. Applied Geography, 84, 23-41. [Google Scholar]

Marçal, M., \& Lima, R. N. (2016). Abordagens Conceituais Contemporâneas na Geomorfologia Fluvial. Espaço Aberto, 6(1), 17-34. [Google Scholar

Montgomery, D. R. (1999). Process domains and the river continuum. JAWRA Journal of the American Water Resources Association, 35(2), 397-410. [Google Scholar]

Oliveira, F. L. (2005). Avaliação ambiental e sustentabilidade da mineração de areia no curso médio-superior do Rio São João, RJ. Dissertação (Mestrado em Geologia. Universidade Federal do Rio de Janeiro, 118, [Google Scholar]

Rosgen, D. L., Catena, r., \& v 22, (1994). A classification of natural. , 3, 169199. [Google Scholar

Neto, S., \& J L, (2005). Decálogo da climatologia do Sudeste brasileiro. Revista Brasileira de Climatologia, v. , 1(1), 41-60. [Google Scholar]

Secretaria, S. (2001). de Estado de Meio Ambiente e Desenvolvimento Sustentável. Bacias Hidrográficas e Rios Fluminenses Síntese Informativa por Macrorregião Ambiental. Rio de Janeiro: SEMADS, [Google Scholar]

Silva, L. C., \& Cunha, H. C. S. (2001). Geologia do Estado do Rio de Janeiro: Texto explicativo do mapa geológico do Estado do Rio de Janeiro. Brasília: CPRM. [Google Scholar]. 